\title{
Allerjik Kontakt Dermatit Kaynă̆ı olan Nikelin İmitasyon Takılardan Dimetilglioksim (DMG) Testi ile Tespiti
}

Determination of Nickel As An Allergic Contact Dermatitis Source From Imitation Jewelry by Dimethylglyoxime (DMG) Test

Selda Mercan

İstanbul Üniversitesi - Cerrahpaşa, Adli Tıp Enstitüsü Fen Bilimleri Anabilim Dalı Adli Toksikoloji Laboratuarı, İstanbul, Türkiye

\begin{abstract}
Özet: En geniş immünolojik organ olan deri, allerjik kontakt dermatit ile çok sık karşılaşmaktadır. Karsinojenik özelliği de olan nikel bileşikleri allerjik kontakt dermatitin en önde gelen kaynağıdır. İnsanlar günlük yaşamlarında imitasyon takılar, bozuk para, saat, gözlük gibi metal objeler ile temas ederek nikele maruz kalmaktadır. Altın, gümüş gibi değerli metallerin yüksek fiyatlı olması, tüketiciyi imitasyon takılara yönlendirmiş ancak kaplamalarında kullanılan nikel bileşenleri nedeniyle bu tür ürünler allerjik kontakt dermatit görülme sıklığını artırmıştır. Bu nedenle metal objelerden salınan nikel için Avrupa Birliği Komisyonu bir kısıtlama getirmiş ve kısa/uzun dönem temas sonucu ortaya çıkabilecek etkilerin azaltılması hedeflenmiștir. Bu çalışmanın amacı İstanbul'da satılmakta olan imitasyon takılardaki nikeli Dimetilglioksim testi ile belirlemek, fiyat ve satış kategorisi ile ilişkisini değerlendirmektir. İstanbul'da 21 farklı satış noktasından, 30 bilezik, 29 kolye, 73 yüzük, 12 hızma, 18 piercing (dil, dudak, kulak kepçesi, göbek için) ve 223 küpe olmak üzere toplam 385 adet takı satın alınmıştır. Objelere yapay ter çözeltisinde bekletilmeden önce ve sonra dimetilglioksim testi uygulanmıştır. Test sonuçlarına göre, 96 objede (\%24.9) nikel tespit edilmiştir. Objeler fiyatlarına göre değerlendirildiğinde, test sonucu pozitif çıkan objelerin fiyatlarının anlamlı bir şekilde daha düşük olduğu bulunmuştur $(\mathrm{p}=0.001)$. Öte yandan markalı zincir mağazalardan alınan takılarda nikel tespit edilme oranının anlamlı şekilde daha düşük olduğu görülmüştür $(\mathrm{p}=0.001)$. Dermatolojik ve uzun vadedeki karsinojenik etkisi nedeni ile özellikle kadınların sıklıkla kullandığı imitasyon objelerdeki nikel konsantrasyonu denetlenmeli ve kontrol altına alınmalıdır. Bu çalışmanın, ülkemizde satılan imitasyon objelerdeki nikelin belirlendiği ilk çalışma olması bakımından, sonraki çalışmalara ve düzenlemelere 1şık tutacağı düşünülmektedir.
\end{abstract}

Anahtar Kelimeler: Nikel, allerjik kontakt dermatit, dimetilglioksim testi, imitasyon tak1

Mercan S. 2019. Allerjik Kontakt Dermatit Kaynağı olan Nikelin İmitasyon Takılardan Dimetilglioksim (DMG) Testi ile Tespiti, Osmangazi Tip Dergisi, 41(4): 397-404 Doi: 10.20515/otd.489500

\begin{abstract}
As the largest immunologic organ, skin is often met allergic contact dermatitis. Nickel compounds are known as carcinogenic and nickel is the main source of allergic contact dermatitis. People are exposed to nickel in daily life through jewelry, metal coins, watches, glasses. The high price of precious metals such as gold and silver headed the consumer to imitation jewelry, however, using such products increased the incidence of allergic contact dermatitis due to the nickel components used in their coatings. Hence, European Commission restricted the nickel release from metal objects and targeted to reduce effects of short and prolonged contact with the skin. The aim of this study was to determine the nickel release by Dimethylglioxime test from imitation jewelry purchased in Istanbul and to consider the nickel release according to price and shopping categories. Imitation jewelry objects $(n=385)$ were purchased from 21 different points in Istanbul with different prices, including 30 bracelets, 29 necklaces, 73 rings, 12 nose rings, 18 piercings (for tongue, lips, external ear, belly button) and 223 earrings. Dimethylglyoxime tests were applied to objects before and after the incubation in artificial sweat solutions. According to the DMG test results, 96 items (\%24.9) were found positive for nickel. Considering the price, the number of nickel releasing objects were significantly higher among low priced objects $(\mathrm{p}=0.001)$. In addition, number of Ni-positive items purchased from chain stores was found significantly lower than others $(\mathrm{p}=0.001)$. Release of nickel in imitation objects, which are generally used by women, should be audited and controlled because of its dermatological and long-term carcinogenic effects. It is thought that this study will guide to further studies and regulations as the first reported study from Turkey.
\end{abstract}

Key Words: nickel, allergic contact dermatitis, dimethylglyoxime, imitation jewelry

Mercan S. 2019. Determination of Nickel As An Allergic Contact Dermatitis Source From Imitation Jewelry by Dimethylglyoxime (DMG) Test, Osmangazi Journal of Medicine, 41(4): 397-404 Doi: 10.20515/otd.489500

ORCID ID of the author: S.M.0000-0002-0431-6972

Kabul Tarihi / Accepted 10.01.2019
Online published 10.01.2019
Yazıșma Adresi / Correspondence Address Selda MERCAN mail: mercans@istanbul.edu.tr 


\section{Giriș}

Doğal bir element olan nikel, gümüşümsü beyaz bir metaldir. Toprakta, kayalarda, suda ve havada bolca bulunmaktadır. Genellikle paslanmaz çelik üretiminde kullanılmakla beraber, elektrik ekipmanları, kozmetik, tak1, ev-iş aletleri, bozuk para üretiminde de kullanılmaktadır. Nikel bileşenleri ayrıca beyaz altının ağartılmasında iyi bir araç olduğundan kuyumculuk sektöründe de sıkça kullanılmaktadır. Organizmadaki nikelin toksikolojik etkisinin daha iyi anlaşılması için nikelin kimyasal ve fiziksel formunun iyi bilinmesi gerekmektedir (1-4).

Uluslararası Kanser Araştırma Ajansı'nın tanımlamasına göre; elementel nikel potansiyel karsinojen olarak Grup 2B sinifina girerken; nikel bileşenleri, özellikle de nikel sülfat, mutlak karsinojen olarak sınıflandırılmış ve Grup 1'e dahil edilmiştir (4). Moleküler düzeyde bakıldığında nikel, kromozom bozukluklarına; özellikle de kromozom kırıklarına ve eksiklerine yol açmaktadır. Nikelin toksik etkileri; kimyasal türüne ve fiziksel formuna bağlı olduğu kadar, maruz kalma yoluna ve konsantrasyonuna da bağlıdır. Nikel maruziyeti, insanlarda oral, inhalasyon ve deri yolu ile gerçekleşmektedir (2). Deri yolu ile maruziyette, nikel içeren bozuk para, takı, anahtar, ev-iş aleti gibi nikel kaplama yapilan metal objeler ana etken olarak bilinmektedir. $\mathrm{Bu}$ tür objelerle sıkça temas edilmesi, nikele deri yolu ile maruz kalınmasına yol açmaktadır. Ter, asidik yapısı nedeni ile metal objelerin deri ile temas ettiği bölgede, içeriğinde bulunan nikel ile reaksiyona girmekte ve nikelin çözünerek deri yolu ile vücuda girmesine yol açmaktadır. Nikel üreten veya işleyen bir işyerinde çalışan insanların genel popülasyondan daha fazla oranda nikel alerjenine, mesleki olarak maruz kaldığı bilinmektedir $(2,3)$. Nikel sülfatın kanserojen etkisinin yanı sıra en yaygın zararlı sağlık etkisi bireylerde nikel hassasiyeti gelişmesi ve buna bağlı ortaya çıkan allerjik kontakt dermatittir $(2,5)$. Allerjik kontakt dermatit, kişinin daha önceden duyarlandığ 1 bir kimyasal ile tekrar karşılaşması sonucu gelişen gecikmiş tipte bir aşırı duyarlılık reaksiyonudur. Kişinin duyarlılık derecesi, allerjen maddenin yapısı ve temas süresine göre değişebilen şiddette kaşıntılı, iyi sınırlı ekzematize bir döküntü gelişmektedir (5).
Nikel allerjisi dünyada allerjik kontakt dermatitin en sik rastlanan nedenleri arasinda ilk sırada yer almaktadır $(5,6)$. Ülkemizde 1585 kişi ile beş yıllık geriye dönük yapılmış bir çalışmada allerjik kontakt dermatitin en sık ellerde görüldüğü ve yama testi pozitif bulunan bireylerde en sik duyarlanmanın nikel sülfata bağlı olduğu saptanmıştır (7). UçarTavlı Y ve ark. (2012), 1038 hasta ile yaptıkları çalışma neticesinde standart seri yama testinde de en sık karşılaşılan alerjenin yine nikel olduğunu saptamışlardır (8). Avrupa popülasyonunda kadınların \%1015 'inin, erkeklerin ise \%2-5'inin nikel allerjisi olduğu bilinmektedir (9). Nikel alerjenine bağlı allerjik kontakt dermatit gelişen bireylerin sayısının gün geçtikçe arttı̆̆ı; bunun sebebinin de nikel salımı fazla olan küpe, toka, kolye, saat, gözlük, bozuk para, cep telefonu, kozmetik ürünler ve ev-iş aletlerinin kullanılmasındaki artış olduğu gösterilmiştir (9-11). Nikel maruziyetinin meydana getirdiği sağlık problemlerinin azaltılması amaciyla Avrupa Birliği Komisyonu cilt ile temas eden metal objelerdeki nikel salımı için bir kısıtlama getirmiş, bu sınır değer 1994 yılında yayınlanan Avrupa Birliği Komisyonu Direktifi'nde (12) $0.5 \mu \mathrm{g} / \mathrm{cm}^{2} /$ hafta olarak belirlenmiş, 2004 yılında yapılan güncelleme ile (2004/96/EC) küpe, piercing, hızma gibi vücuda penetre olan objeler için, $<0.2$ $\mu \mathrm{g} / \mathrm{cm}^{2} /$ hafta olarak değiştirilmiştir (12).

2012 yılında Junping Y ve ark. "Nikel allerjisi yapmaz" etiketli 10 ayar beyaz altın takılardan salınan nikel oranlarını araştırmıştır. Farklı 1sı uygulamaları ve yüzey muamele yöntemleri kullanılmış olan takılardan birçoğu 94/27/EC'nin belirlediği sınırın altında kalırken $\left(<0.5 \mu \mathrm{g} / \mathrm{cm}^{2} /\right.$ hafta $), 2004 / 96 /$ EC'nin kriterlerine uymamıştır $\left(<0.2 \mu \mathrm{g} / \mathrm{cm}^{2} /\right.$ hafta $)$. $\mathrm{Bu}$ ürünlerin, özellikle hızma, küpe gibi penetre olan (piercing) 10 ayar beyaz altın takıların dahi nikel allerji riski yaratabileceği bildirilmiştir (13). Nikel allerjisi yapmadığı tescillenmiş 10 ayar beyaz altın ürünlerde dahi nikel direktifleri ile uyumsuz sonuçlar elde edilmesi, imitasyon takilarda bu durumun daha ciddi boyutlarda olabileceği gerçeğini ak1llara getirmektedir. 
Metal objelerdeki nikelin varlığını tespit etmek için kullanılan birkaç yöntemden bir tanesi olan Dimetilglioksim (DMG) nikel spot testi, nikel salımını kalitatif olarak tayin eden en ucuz ve en hizlı yöntemdir. Uygulaması basit bir yöntem olması nedeniyle tüketici, satıcı ve dermatologlar için de oldukça avantajlıdır. Yüksek seçiciliğe ve orta düzeyde duyarlılığa sahip bir organik çöktürücü olan bu test, zayıf bazik çözeltide, sadece Nikel (II) iyonlarını çöktürmektedir. Tespit limiti yaklaşık $0,5 \mu \mathrm{gg} / \mathrm{cm}^{2} / \mathrm{hafta}$ bulunmuştur $(14,15)$. Metal objeye zarar vermeksizin yapilabilen bir test olduğundan pek çok çalışmada tercih edilen bir yöntemdir $(14,16)$.

Ülkemizde yayımlanan 14 Ocak 2015 tarihli 29236 say1l Resmi Gazete'de belirtilen, piyasaya nihai ürün olarak arz edilen bazı tüketici ürünlerinde kullanılan tehlikeli kimyasal maddelerin kullanımının sınırlandırılmasına ilişkin usul ve esasların düzenlendiği tebliğe ek bir tebliğg, Gümrük ve Ticaret Bakanlığı tarafından yayınlanmış ve nikel alerjeni Avrupa Birliği Komisyonu Direktifi'nde belirtilen limitlerle bu listeye ilave edilmiştir. Takılarda ve metal objelerde nikel varlığını konu alan ve nikel hassasiyetinin dış etkenlerinin iyileștirilmesi ile ilgili yapılmış dünya literatüründe çok sayıda çalışma bulunmaktayken, ülkemizde satılmakta olan imitasyon takılarla ilgili yapılmış herhangi bir çalışmaya literatür taraması dahilinde henüz rastlanmamıştır.

Ülkemizde bu alandaki boşluğu doldurmak adına, bu çalışmada İstanbul piyasasında satılan küpe, hızma, piercing, kolye, yüzük ve bilezik gibi imitasyon takılardaki nikel alerjeninin varlığının Dimetilglioksim (DMG) testi ile belirlenmesi amaçlanmıştır.

\section{Gereç ve Yöntemler}

\section{Örneklerin toplanması ve sinıflandırılması}

Bu çalışma, 3 Eylül 2013 tarihli toplantıda İ.Ü. Cerrahpaşa Tıp Fakültesi Klinik Araştırmalar Etik Kurulu tarafından uygun bulunmuştur (Kara No: A-30). Çalışmada toplam 21 farklı satış noktası olmak üzere, İstanbul'un çeşitli semt pazarlarından, sokak arası aksesuar mağazalarından, süper marketlerden ve ticari markalı aksesuar satan mağazalar zincirinden farklı fiyatlara satılan; 30 adet bilezik, 29 adet kolye, 73 adet yüzük, 12 adet hizma, 18 adet piercing (dil, dudak, kulak kepçesi, göbek için) ve 223 çift küpe olmak üzere toplam 385 adet imitasyon tak1 satın alındı. Küpe, hızma ve piercing ürünlerin tamamının penetre olma özelliği arandı. Satış görevlilerinden yardım alınarak en çok satılan ürünler rastgele seçildi, aynı üründen ikinci bir tane daha satın alınmadı ve üzerinde "nikel içermez", "allerji yapmaz" vb uyarılar olan ürünler satın alınmadı. Ürünlerin tamamının genç ve yetişkin kadınlara yönelik olmasına özen gösterildi. Bakır, gümüş ve altın takılar çalışmaya dahil edilmedi. 385 adet ürün için 2014 y1lında toplam 2850 TL ödendi. Tüm takılar için 1 TL'den düşük ve 20 TL'den yüksek fiyata sahip olan ürünler satın alınmadı. Takılar satın alındığı yere göre semt pazar1, market-sokak aras1 aksesuar mağazaları ve ticari markalı zincir mağazalar olmak üzere 3 grupta değerlendirilirken; fiyatlarına göre ise $<5 \mathrm{TL}, 5-10 \mathrm{TL}$ ve $10-20$ TL olmak üzere yine 3 grupta değerlendirildi. $\mathrm{Bu}$ çalışma

\section{Çalışma çözeltilerinin hazırlanması}

Çalışmada kullanılan tüm çözeltiler testin uygulandığı gün taze olarak hazırlandı. Dimetilglioksim çözeltisinin hazırlanması $(\% 0.8 \mathrm{~m} / \mathrm{V})$ için $0.84 \mathrm{~g}$ dimetilglioksim $(2,3-$ butandion oksim), \% 95'lik $100 \mathrm{~mL}$ mutlak etil alkolde çözülerek hazırlandı. Çözeltinin aktivitesini kontrol etmek üzere bozuk para kullanılarak örnek uygulama yapıldı. Amonyak çözeltisi (\%10) için \%32 $\mathrm{NH}_{3}^{\prime}$ ten $31.25 \mathrm{~mL}$ alınarak, $100 \mathrm{~mL}$ ultra saf su ile hacme tamamlandi. Takıların dış kontaminasyondan arındırılması için kullanılan sodyum dodesil sülfat (SDS) çözeltisinin (\%0.5) hazırlanması için ise, $0.5 \mathrm{~g}$ SDS tartılarak $100 \mathrm{~mL}$ ultra saf su içinde tamamen çözününceye kadar vorteks karıştırıcı yardımı ile karıştırıldı ve son hacim kontrol edilerek hacme tamamland. Yapay ter çözeltisinin hazırlanması için EN1811:2011 direktifinden yararlanılarak (17) $1 \mathrm{~g}$ üre, $5 \mathrm{~g}$ $\mathrm{NaCl}$ ve $920 \mu \mathrm{L}$ laktik asit (ağırlıkça $\% 0.5$ $\mathrm{NaCl}, \% 0.1$ üre, \%0.1 laktik asit), $1000 \mathrm{~mL}$ hacimli bir balon joje içinde bir miktar ultra saf su ile karıştırıldı ve \%1 seyreltik amonyak 
ile pH:6.5 \pm 0.1 'e ayarlanarak ultra saf su ile hacme tamamlandi. Yapay ter çözeltisi kullanmadan en fazla 3 saat önce hazırland.

DMG testinin uygulanmasl (CR 12471:2002 E) (18)

Satın alınan imitasyon takılar fotoğraflanarak numaralandırıldı. Dış kontaminasyondan ve el temasından kaynaklanacak kirliliği azaltmak üzere tüm ürünler \%0.5 SDS çözeltisi ile ultrasonik banyoda 10 dakika boyunca muamele edildi ve etüvde kurumaya bırakıldı. Kuruyan imitasyon objelerin cilt ile temas eden noktalarına (küpe, piercing ve hızmaların deriye penetre olduğu kısımlara, yüzüklerin iç kısımlarına, kolyelerin boyuna, bilekliklerin ise bileğe temas ettiği bölgelere) DMG testi uyguland.

Y1kanıp kurutulan takılardaki nikel varlığını tespit etmek üzere uygulanan DMG testi için, ucu pamuklu çubuklara plastik pastör pipet yardımı ile 2 damla DMG çözeltisi, 1 damla amonyak çözeltisi damlatıldı ve pamuğun beyaz renkli olduğundan emin olunduktan sonra imitasyon takının kullanım yerine göre cilt ile temas eden bölgesi bu pamuklu çubuk ile 30 saniye boyunca silindi. Pamuklu çubuk beyaz zemin üzerinde kurumaya birakıldı ve renk değişimi gözlendi. Açık pembe ile kırmızı arasında bir renk gözlenmesi durumunda test sonucu pozitif olarak değerlendirildi. Herhangi bir renk değişikliği gözlenmeyen takılar için test sonucu negatif olarak kaydedildi. Kırmızı-kahverengi, kahverengi veya yeşil-kahverengi renk gözlemlenen takılar için DMG testi şüpheli olarak kaydedildi. DMG testinin değerlendirilmesine ilişkin örnek uygulamalar Şekil 1'de görüldüğü gibidir. İlk DMG testinin uygulanmasinın ardından CR 12471:2002 E standardında belirtildiği üzere tüm imitasyon objeler yapay ter çözeltisi içerisinde 1 hafta (168 saat) boyunca $30 \pm 1^{\circ} \mathrm{C}^{\prime} \mathrm{de}$ su banyosunda inkübe edildi. Bir haftalık inkübasyon sonrası takılar yapay ter çözeltisinden çıkarıldı ve ultra saf su ile yıkanarak etüvde kurutuldu ve taze hazırlanmış DMG test çözeltisi ile yukarıda belirtildiği şekilde yeniden test edildi.

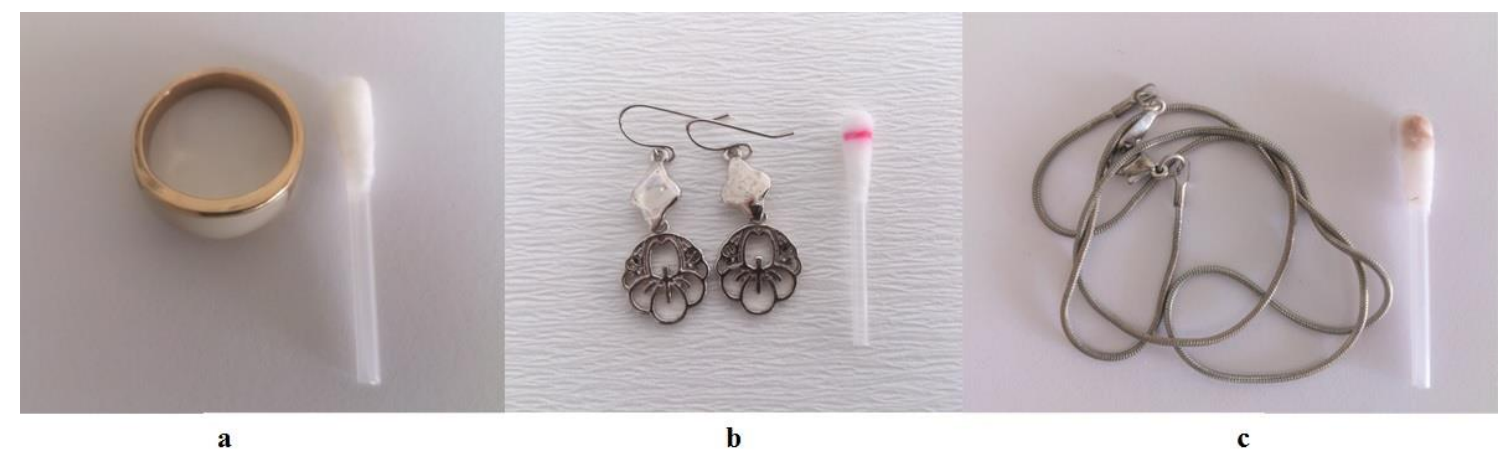

Şekil 1. Negatif (a), pozitif (b) ve şüpheli (c) bulunan DMG test sonuçlarından örnekler

\section{İstatistiksel analiz}

Tüm verilerin istatistiksel değerlendirmesi için tanımlayıcı analiz, ve Ki-kare $\left(\mathrm{X}^{2}\right)$ testi uygulanmış ve analizler Windows tabanlı SPSS 16.0 (SPSS for Windows, Version 16.0. Chicago, SPSS Inc.) programı kullanılarak yapılmıştır. Anlamlılık düzeyi $p<0.05$ olarak kabul edilmiştir.

\section{Bulgular}

İmitasyon takılar alındığı yere ve fiyata göre gruplandırılarak ayrıntıları Tablo 1'de sunulmuştur.

Toplam 385 imitasyon tak1 ile yapılan çalışmada önce ilk basamak DMG testi uygulanmış, ardından takılar yapay ter çözeltisinde bir hafta inkübe edilerek ikinci basamak DMG testi uygulanmıştır. Her iki test sonucuna ait bulgular Tablo 2'deki gibi listelenmiştir. Elde edilen bulgular birinci basamakta yapılan DMG testinde nikel salımı 
pozitif olan objelerin sayısının ( $\mathrm{n}=96)$ yapay terde bekletildikten sonra ikinci kez yapılan DMG testine göre daha fazla olduğunu gösterdi $(n=61)$. Yapılan iki DMG testinin sonuçlarına bakıldığında genel itibari ile DMG testi pozitif ve şüpheli bulunan objelerin sayısında düşüş, negatif bulunanların sayısında ise artış olduğu görülmektedir. Öte yandan ilk test sonucuna göre şüpheli renk veren toplam 31 takının 22'sinin, yapay terde bekletildikten sonra yapilan ikinci testte negatif bulunduğu, 3'ünün pozitif bulunduğu geri kalanın ise aynı kaldığ 1 görülmüştür, bu durumun metal objenin demir, bakır, kobalt paladyum gibi elementler bakımından zengin olmasından kaynaklandığı düşünülmüştür (18). Göze çarpan bulgulardan bir diğeri ise piercing türü takıların tümünün her iki test sonucunun da fiyatı ve alındığ 1 yer fark etmeksizin negatif olmasıdır. Bir diğer dikkat çeken husus ise, hızma ve küpelerin pozitif bulunma yüzdelerinin kolye, yüzük ve bilezikte elde edilen yüzdelere göre daha düşük olmasıdır. Bu durumda vücuda penetre olan ürünlerde allerjik kontakt dermatit riskinin çok daha yüksek olmasının üreticinin nikel kullanımında caydırıcı etki yarattığı söylenebilir.

Yapay ter öncesi ve sonrası yapılan DMG testinin sonucu pozitif bulunan takıların alındığı yer ve fiyat sinıflandırmasına göre dağılımı Tablo 3'teki gibidir. Takıların satın alındığı yerlere göre DMG sonuçları karşılaştırıldığında; 21 farklı satış noktasından sadece bir tanesinden alınan imitasyon takılarda DMG testi sonucunda nikel tespit edilmediği (\%4.76) ve bu satış noktasının da ticari markalı aksesuar satan mağazalar zinciri olduğu görülmüsstür. İmitasyon takıların alındığı yer ile her iki DMG test sonucu arasındaki ilişkiye bakıldığında, hem yapay ter öncesi hem de yapay ter sonras1 yapilan DMG test sonuçlarına göre pozitif bulunan takıların sayısının ticari markalı zincir mağazalardan alınanlarda anlamlı düzeyde düşük bulunduğu $(p=0.001)$; sokak aras1 mağazalar-süper marketlerden alınanlarda ise anlamlı düzeyde yüksek bulunduğu görülmüştür $(p=0.001)$. Semt pazarlarından alınan ve her iki DMG test için pozitif sonuç bulunan takıların sayıs1 arasında ise anlaml bir ilişki bulunmamıştır $(p>0.05)$. Pozitif bulunan DMG test sonuçları ile fiyat arasındaki ilişki değerlendirildiğinde; hem yapay ter öncesi hem de yapay ter sonras1 yapılan DMG testi pozitif sonuçlarının düşük fiyat kategorisindeki takılar için anlamlı düzeyde yüksek bulunduğu ( $p=0.001)$, yüksek fiyat kategorisindeki takılar için ise anlamlı düzeyde düşük olduğu $(p=0.001)$ tespit edilmiştir. Fiyatı 5-10 TL olan takılar arasında DMG testi pozitif olan takıların sayısı ile bu fiyat kategorisi arasında anlamlı bir sonuç elde edilmemiştir $\quad(p>0.05)$.

Tablo 1.

İmitasyon takıların alındığı yere ve fiyata göre sınıflandırması

\begin{tabular}{|c|c|c|c|c|c|c|}
\hline \multirow[b]{2}{*}{ Takı Türü } & \multicolumn{3}{|c|}{ Alındığı yere göre } & \multicolumn{3}{|c|}{ Fiyata göre } \\
\hline & $\begin{array}{c}\text { Semt } \\
\text { pazarları } \\
(\mathbf{n}=\mathbf{3})\end{array}$ & $\begin{array}{c}\text { Sokak arası } \\
\text { mağazalar } \\
(n=9)\end{array}$ & $\begin{array}{c}\text { Ticari } \\
\text { markalı } \\
\text { zincir } \\
\text { mağazalar } \\
(\mathbf{n}=9)\end{array}$ & $<5 \mathrm{TL}$ & $\begin{array}{l}\geq 5 \mathrm{TL}- \\
<10 \mathrm{TL}\end{array}$ & $\geq 10-<20 \mathrm{TL}$ \\
\hline $\begin{array}{c}\text { Piercing } \\
(n=18)\end{array}$ & - & 14 & 4 & 13 & 5 & 0 \\
\hline $\begin{array}{c}\text { Hizma } \\
(n=12)\end{array}$ & 2 & 8 & 2 & 7 & 5 & 0 \\
\hline $\begin{array}{l}\text { Bilezik } \\
(n=30)\end{array}$ & 4 & 17 & 9 & 7 & 9 & 14 \\
\hline $\begin{array}{l}\text { Yüzük } \\
(n=73)\end{array}$ & 20 & 36 & 17 & 37 & 16 & 20 \\
\hline $\begin{array}{l}\text { Kolye } \\
(n=29)\end{array}$ & 4 & 17 & 8 & 5 & 5 & 19 \\
\hline Küpe & 41 & 135 & 47 & 94 & 91 & 38 \\
\hline
\end{tabular}




\begin{tabular}{ccccccc}
\hline $\mathbf{n}=\mathbf{2 2 3})$ & \multicolumn{7}{c}{} \\
\hline Toplam & 71 & 227 & 87 & 163 & 131 & 91 \\
$(\mathbf{n}=385)$ & $(\% 18.4)$ & $(\% 59.0)$ & $(\% 22.6)$ & $(\% 42.3)$ & $(\% 34.0)$ & $(\% 23.6)$ \\
\hline
\end{tabular}

Tablo 2.

İmitasyon takıların yapay ter öncesi ve sonrası DMG test sonuçları ve yüzdeleri

\begin{tabular}{|c|c|c|c|c|c|c|}
\hline \multirow{2}{*}{ Takı Türü } & \multicolumn{3}{|c|}{ Yapay ter öncesi DMG testi (\%) } & \multicolumn{3}{|c|}{ Yapay ter sonrası DMG testi (\%) } \\
\hline & Pozitif & Negatif & Şüpheli & Pozitif & Negatif & Şüpheli \\
\hline $\begin{array}{c}\text { Piercing } \\
(n=18)\end{array}$ & - & $\begin{array}{c}18 \\
(100)\end{array}$ & - & - & $\begin{array}{c}18 \\
(100)\end{array}$ & - \\
\hline $\begin{array}{l}\text { Hızma } \\
(n=12)\end{array}$ & $\begin{array}{c}2 \\
(16.7)\end{array}$ & $\begin{array}{c}10 \\
(83.3)\end{array}$ & - & $\begin{array}{c}2 \\
(16.7)\end{array}$ & $\begin{array}{c}10 \\
(83.3)\end{array}$ & - \\
\hline $\begin{array}{l}\text { Bilezik } \\
(n=30)\end{array}$ & $\begin{array}{c}11 \\
(36.7)\end{array}$ & $\begin{array}{c}14 \\
(46.7)\end{array}$ & $\begin{array}{c}5 \\
(16.7)\end{array}$ & $\begin{array}{c}3 \\
(10.0)\end{array}$ & $\begin{array}{c}26 \\
(86.7)\end{array}$ & $\begin{array}{c}1 \\
(3.3)\end{array}$ \\
\hline $\begin{array}{l}\text { Yüzük } \\
(n=73)\end{array}$ & $\begin{array}{c}25 \\
(34.2)\end{array}$ & $\begin{array}{c}44 \\
(60.3)\end{array}$ & $\begin{array}{c}4 \\
(5.5)\end{array}$ & $\begin{array}{c}16 \\
(21.9)\end{array}$ & $\begin{array}{c}57 \\
(78.1)\end{array}$ & - \\
\hline $\begin{array}{l}\text { Kolye } \\
(n=29)\end{array}$ & $\begin{array}{c}8 \\
(27.6)\end{array}$ & $\begin{array}{c}18 \\
(62.1)\end{array}$ & $\begin{array}{c}3 \\
(10.3)\end{array}$ & $\begin{array}{c}2 \\
(6.9)\end{array}$ & $\begin{array}{c}25 \\
(86.2)\end{array}$ & $\begin{array}{c}2 \\
(6.9)\end{array}$ \\
\hline $\begin{array}{c}\text { Küpe } \\
(\mathbf{n}=\mathbf{2 2 3})\end{array}$ & $\begin{array}{c}46 \\
(20.6)\end{array}$ & $\begin{array}{c}158 \\
(70.9)\end{array}$ & $\begin{array}{c}19 \\
(8.5)\end{array}$ & $\begin{array}{c}38 \\
(17.0) \\
\end{array}$ & $\begin{array}{c}182 \\
(81.6)\end{array}$ & $\begin{array}{c}3 \\
(1.3) \\
\end{array}$ \\
\hline $\begin{array}{l}\text { Toplam } \\
(\mathbf{n}=\mathbf{3 8 5})\end{array}$ & $\begin{array}{c}96 \\
(24.9) \\
\end{array}$ & $\begin{array}{c}258 \\
(67.0) \\
\end{array}$ & $\begin{array}{c}31 \\
(8.1) \\
\end{array}$ & $\begin{array}{c}61 \\
(15.8) \\
\end{array}$ & $\begin{array}{c}318 \\
(82.6) \\
\end{array}$ & $\begin{array}{c}6 \\
(1.6) \\
\end{array}$ \\
\hline
\end{tabular}

Tablo 3.

Nikel tespit edilen takıların alındığı yere ve fiyata göre dağılımı

\begin{tabular}{|c|c|c|c|c|c|c|}
\hline & \multicolumn{3}{|c|}{ Alındığı yere göre } & \multicolumn{3}{|c|}{ Fiyata göre } \\
\hline DMG test türü & $\begin{array}{c}\text { Semt } \\
\text { pazarları } \\
(n=71)\end{array}$ & $\begin{array}{c}\text { Sokak arası } \\
\text { mağazalar } \\
(n=227)\end{array}$ & $\begin{array}{c}\text { Ticari } \\
\text { markalı } \\
\text { zincir } \\
\text { mağazalar } \\
(\mathbf{n}=87)\end{array}$ & $\begin{array}{l}<5 \mathrm{TL} \\
(\mathrm{n}=163)\end{array}$ & $\begin{aligned} &>5 \text { TL- } \\
&< 10 \mathrm{TL} \\
&(n=131)\end{aligned}$ & $\begin{array}{l}>10-<20 \\
\text { TL } \\
(n=91)\end{array}$ \\
\hline $\begin{array}{l}\text { Yapay ter } \\
\text { öncesi }(n=96)\end{array}$ & 37 & 51 & 8 & 50 & 29 & 17 \\
\hline $\begin{array}{l}\text { Yapay ter } \\
\text { sonrasi }(n=61)\end{array}$ & 23 & 33 & 5 & 35 & 18 & 8 \\
\hline
\end{tabular}

\section{Tartışma}

Nikel alerjeninin sebep olduğu allerjik kontakt dermatitin en önemli kaynakları metal objeler, metal kaplama ürünler, bozuk para ve imitasyon takılardır. Metal objelerin yüzey kaplamalarındaki veya alaşımlarındaki nikel, uzun süreli ve tekrarlayan temas sonucunda insan terinin korozif gücü ile bir objedeki (saat, küpe, bozuk para vb.) metalin deriye difüze olmasına neden olmaktadır (9). Bu da objenin nikel salım miktarına göre değişmekle birlikte deri yüzeyinde birikime ve deri yolu ile absorbsiyonuna yol açmaktadır. Böylelikle allerjik kontakt dermatit, nikel duyarlanması olan bireylerde ilk kullanımın ardından gelişmekte, duyarlanma olmayan bireylerde ise tekrarlayan veya uzun süren temas sonucu nikel duyarlanması meydana gelmektedir (5). $\mathrm{Bu}$ çalışmada da pozitif bulunduğu halde ikinci test sonrası negatif bulunan takıların üst yüzeylerindeki nikel kaplama, yapay terde bir hafta bekletildikten sonra DMG testinin tespit limiti olan $0,5 \mu \mathrm{g} / \mathrm{cm}^{2} /$ hafta değerin altına düşse de tak1 ilk kullanıldığ 1 andan itibaren nikel duyarlılığı olan bireylerde allerjik kontakt dermatit reaksiyonu geliştireceğinden, ilk testten elde edilen bulgunun tüketici yönünden değerlendirildiğinde daha kıymetli olduğu düşünülmektedir. Çalışmadan elde 
edilen verilerin genel toplamına bakıldığında her dört imitasyon takıdan birinin DMG testinin tespit limiti olan $0,5 \mu \mathrm{g} / \mathrm{cm}^{2} / \mathrm{hafta}$ değerinin üzerinde nikel içerdiği görülmüştür. Ayrica imitasyon tak1 satan toplam 21 mağazanın \%95.2'sinin allerjik kontakt dermatite neden olabilecek objeleri sattığ belirlenmiştir. Öte yandan ürünlerin düşük fiyatlara satılmasının nikel salımı olma riskini arttırdığı görülmüştür. Şüpheli bulunan DMG testi sonuçlarının yapay ter öncesinde toplam sayısının 31 iken, yapay ter sonras 22 objenin negatif sonuç vererek şüpheli ürün sayısının 6'ya düşmesi de bu tür şüpheli örneklerin büyük oranda demir, bakır gibi elementleri içerdiği, nikel varlığı açısından ise önem arz etmediği kanaatine varılmıştır.

Her ne kadar ülkemizde olmasa da, imitasyon takılarda ve aksesuardaki nikel salımı ile ilgili farklı ülkelerde yapılan pek çok çalışma bulunmaktadır. Danimarka'da yapılan bir çalışmada toplam 354 adet ucuz imitasyon tak1 ve saç tokası üzerine yapılan DMG testi neticesinde; saç tokalarının $(\mathrm{n}=117)$ $\% 19.3$ 'ünde, küpelerin $(\mathrm{n}=170) \% 14.8$ 'inde, kolyelerin $(\mathrm{n}=33) \% 12.9$ 'unda, yüzüklerin $(\mathrm{n}=16) \% 20$ 'sinde, bileziklerin $(\mathrm{n}=18)$ ise \%11.1'inde sınırın üzerinde nikel olduğu tespit edilmiş, ayrıca takıların satın alındığı mağazaların \%36'sının bu ürünleri sattığ 1 bildirilmiştir (16). Thyssen ve ark. tarafindan yapılan çalışmadan elde edilen sonuçlar bu çalışmadan elde edilen sonuçlarla karşılaştırıldığında; İstanbul'da imitasyon takı satmakta olan ve çalışmaya dahil edilen 21 satış noktasından sadece bir tanesinin 0.5 $\mu \mathrm{g} / \mathrm{cm}^{2} /$ hafta olarak belirlenen nikel salım limitinin altında ürünler sattığ1 görülmektedir. Öte yandan bu çalışmada nikel salımı olduğu tespit edilen küpelere \%20.6, kolyelere $\% 27.6$, bileziklere $\% 36.7$, yüzüklere ise $\% 34.2$ s1klıkta olmak üzere daha fazla oranda rastlanmıştır.

Bocca vd. (2007) İtalya piyasasında mevcut olan imitasyon küpelerdeki nikel ve diğer alerjen metallerin içeriğini ve nikel salınmasını araştırmıştır. Yapılan araştırmada piyasadan toplanan küpelerin $\% 50$ 'sinde $\mathrm{Ni}$ mevzuatına uyulmadığı, küpelerde nikelin yanı sıra; çinko, mangan, kurşun, bakır, alüminyum, kadmiyum gibi elementlerin de salınmakta olduğu bildirilmiştir (9). Yönetmeliklerin öngördüğü sınırın üzerindeki nikelin küpelerdeki varlığını tespit etmek için yapılan bir başka uluslararası çalışmada Amerika, Meksika, Tayland ve Çin menşeli toplam 277 imitasyon küpe ile bir çalışma yapılmış, ürünlerin \%30.7'sinde DMG testi pozitif bulunmuş, imalat yeri ve ürün fiyatı ile nikel varlığı arasında bir ilişki bulunmamıştır. Ayrıca, nikel içeriği pozitif çıkan küpelerin satıldığı mağazaların daha çok genç kadınlara hitap eden yerler olduğu tespit edilmiştir. $\mathrm{Bu}$ çalışma imitasyon takı satın alırken güvenlik sınırı olarak kabul edilebilecek bir fiyat limitinin belirlenemediğini ortaya koymuştur (14). Benzer bir diğer çalışmada Çin ve Tayland menşeli 557 küpeye DMG testi uygulanmış ve küpelerin ortalama \%30.4'ünde nikel tespit edilmiştir (11). Bulgular karşılaştırıldığında bu çalışmada yer alan 223 küpeden 46'sının (\%20.6) DMG testinin pozitif bulunarak yukarıda bahsi geçen üç farklı araştırmaya göre daha düşük oranda nikel içeren ürün olduğu ve ürünlerin fiyatları ve alındığı yer ile nikel salımı arasında anlamlı bir ilişki olduğu görülmüştür. Her ne kadar duyarlılığı orta düzeyde olsa da (15) DMG testinin objeye zarar vermeden yapılıyor olması, kısa sürede yapılabilen ve ucuz bir yöntem olması bu testi avantajlı hale getirmektedir ve bu test nikelin kalitatif tayini için ilk başvurulan yöntemdir.

\section{Sonuc}

Sonuç olarak nikel, günlük yaşantıda sıkça temas halinde olduğumuz ve kısa/uzun vadeli toksik etkileri nedeni ile maruziyetinin tüm alanlarda en aza indirilmesi gereken bir elementtir. Özellikle sokak arası takı satan mağazalardan alınan ve düşük fiyata satılan ürünlerle nikel salımı arasında anlamlı bir ilişki olduğu sonucuna varılmıştır. Dermatolojik etkileri ve uzun vadedeki karsinojenik etkisi nedeni ile özellikle kadınların sıklıkla kullandığ 1 imitasyon objelerdeki nikel konsantrasyonu denetlenmeli ve kontrol altına alınabilmelidir. $\mathrm{Bu}$ da, öncelikle tüketicinin bu konudaki bilgi düzeyinin arttırılmas1, yürürlüğe koyulan yönetmelikler 1şığında düzenli denetimin ve iyileştirilmenin yapılması ve bu alanda 
yapılan çalışmaların sayısının artması ile sağlanabilecektir.

\section{Teşekkür}

Bu çalışma TUBITTAK tarafindan, 2135098 numaralı proje ile ve İ.Ü-Cerrahpaşa Bilimsel
Araştırma Projeleri Birimi tarafindan BYP54488 numarall proje ile desteklenmiştir. Çalışmanın istatistik değerlendirmelerine katkı sağlayan Doç. Dr. Hayriye VEHID'e ve teknik desteklerinden ötürü Murat YAYLA ve Sevcan ŞEMEN'e teşekkür ederim.

\section{KAYNAKLAR}

1. Denkhaus E, Salnikow K. Nickel essentiality, toxicity, and carcinogenicity. Critical Reviews in Oncology/Hematology. 2002; 42: 35-56.

2. Cempel M, Nikel G. Nickel: A review of its sources and environmental toxicology. Polish J of Environ Stud 2006; 15(3): 375382.

3. Schaumlöffel D. Nickel species: Analysis and toxic effects. Journal of Trace Elements in Medicine and Biology. 2012; 26: 1-6.

4. International Agency for Research on Cancer (IARC), 1990. Monograph on the evaluation of carcinogenic risks to humans. Chromium, nickel and welding, vol 49, Lyon, ISBN 9283212495.

5. Mowad CM, Marks Jr JG. (2012) Allergic Contact Dermatitis in Bolognia JL, Jorizzo JL, Schaffer JV. Editors. Dermatology. 3rd ed. London: Elsevier; pp. 233-248.

6. Boonchai W, Maneeprasopchoke P, Suiwongsa B, Kasemsarn P. Assessment of nickel and cobalt release from jewelry from a non-nickel directive country. Dermatitis. 2015; 26(1): 44-48.

7. Doğramac1 AÇ, Gürer MA. Kontakt dermatitli hastalarda yama testi sonuçları: Beş y1llık retrospektif çalışma. Türkiye Klinikleri J Dermatol. 2008; 18: 215-22.

8. Uçar-Tavlı Y, Mevlitoğlu İ, Şahin TK, Daye M. Beş yıllık yama testi sonuçlarımız. Genel Tip Derg. 2012; 22(1): 16-20.

9. Bocca B, Forte G, Senofonte O, et al. A pilot study on the content and the release of $\mathrm{Ni}$ and other allergenic metals from cheap earrings available on the Italian market. Science of the Total Environment. 2007; 388: 24-34.

10. Thyssen JP, Menné T. Metal allergy-A review on exposures, penetration, genetics, prevalence, and clinical implications. Chem. Res. Toxicol. 2010; 23(2): 309-318.
11. Hamann CR, Hamann DJ, Hamann QJ, et al. Assessment of nickel release from earrings randomly purchased in China and Thailand using the dimethylglyoxime test. Contact Dermatitis. 2010; 62:232-240.

12. Commission Directive 2004/96/EC of 27 September 2004 amending Council Directive 76/769/EEC as regards restriction on the marketing and use of nickel for piercing post assemblies for the purpose of adapting its Annex I to technical progress. Official Journal L 301.

13. Junping Y, Wei L, Chang W. Nickel release of $10 \mathrm{~K}$ white gold alloy for jewelry. Rare Metal Materials and Engineering. 2012; 41(6): 0947-0951.

14. Thyssen JP, Maibach HI. Nickel release from earrings purchased in the United States: The San Francisco earring study. J Am Acad Dermatol. 2008; 58: 1000-5.

15. Thyssen JP, Skare L, Lundgren L. Sensitivity and specificity of the nickel spot (dimethylglyoxime) test. Contact Dermatitis. 2010; 62: 279-288.

16. Thyssen JP, Menné T, Johansen JD. Nickel release from inexpensive jewelry and hair clasps purchased in an EU country - Are consumers sufficiently protected from nickel exposure? Science of the Total Environment. 2009; 407: 5315-5318.

17. European nickel release standard, EN 1811:2011+A1:2015, defined the test method and criteria for compliance with the REACH Annex XVII requirements for nickel release.

18. Technical Committee CEN/TC 283, (2002) Screening tests for nickel release from alloys and coatings in items that come into direct and prolonged contact with the skin (CR 12471:2002), ISBN: 0580404862 